\title{
Prenatal Nicotine Exposure Impairs the Proliferation of Neuronal Progenitors, Leading to Fewer Glutamatergic Neurons in the Medial Prefrontal Cortex
}

\author{
Yuki Aoyama ${ }^{1,2}$, Kazuya Toriumi ${ }^{2}$, Akihiro Mouri ${ }^{2,3}$, Tomoya Hattori ${ }^{2}$, Eriko Ueda ${ }^{2}$, Akane Shimato ${ }^{2}$, \\ Nami Sakakibara", Yuka Soh ${ }^{2}$, Takayoshi Mamiyaa, ${ }^{2,3}$, Taku Nagai', Hyoung-Chun Kim', Masayuki Hiramatsu', \\ Toshitaka Nabeshima*,3,5 and Kiyofumi Yamada*,1,3 \\ 'Department of Neuropsychopharmacology and Hospital Pharmacy, Graduate School of Medicine, Nagoya University, Nagoya, Japan; \\ ${ }^{2}$ Department of Chemical Pharmacology, Faculty of Pharmacy, Meijo University, Nagoya, Japan; ${ }^{3} J a p a n e s e$ Drug Organization of Appropriate Use \\ and Research, Nagoya, Japan; ${ }^{4}$ Department of Neuropsychopharmacology and Toxicology Program, College of Pharmacy, Kangwon National \\ University, Chunchon, South Korea; ${ }^{5}$ Nabeshima Laboratory, Faculty of Pharmacy, Meijo University, Nagoya, Japan
}

\begin{abstract}
Cigarette smoking during pregnancy is associated with various disabilities in the offspring such as attention deficithyperactivity disorder, learning disabilities, and persistent anxiety. We have reported that nicotine exposure in female mice during pregnancy, in particular from embryonic day 14 (EI4) to postnatal day 0 (PO), induces long-lasting behavioral deficits in offspring. However, the mechanism by which prenatal nicotine exposure (PNE) affects neurodevelopment, resulting in behavioral deficits, has remained unclear. Here, we report that PNE disrupted the proliferation of neuronal progenitors, leading to a decrease in the progenitor pool in the ventricular and subventricular zones. In addition, using a cumulative 5-bromo-2'-deoxyuridine labeling assay, we evaluated the rate of cell cycle progression causing the impairment of neuronal progenitor proliferation, and uncovered anomalous cell cycle kinetics in mice with PNE. Accordingly, the density of glutamatergic neurons in the medial prefrontal cortex (medial PFC) was reduced, implying glutamatergic dysregulation. Mice with PNE exhibited behavioral impairments in attentional function and behavioral flexibility in adulthood, and the deficits were ameliorated by microinjection of D-cycloserine into the PFC. Collectively, our findings suggest that PNE affects the proliferation and maturation of progenitor cells to glutamatergic neuron during neurodevelopment in the medial PFC, which may be associated with cognitive deficits in the offspring.

Neuropsychopharmacology (2016) 4I, 578-589; doi: 10.1 1038/npp.20I5.186; published online 22 July 2015
\end{abstract}

\section{INTRODUCTION}

Several reports have associated cigarette smoking during pregnancy with neurobehavioral impairments, including attention deficit/hyperactivity disorder (AD/HD), learning disabilities, cognitive dysfunction, and persistent anxiety in the offspring (Pagani, 2014). Nicotine, among the inhaled components of cigarette smoke, is thought to be the main effector of these behavioral impairments because of its actions on nicotinic acetylcholine receptors (nAChRs) in the developing fetal and mature brain (Pauly and Slotkin, 2008). nAChRs, which are pentameric ligand-gate cation channels made up of

*Correspondence: Dr T Nabeshima, Nabeshima Laboratory, Faculty of Pharmacy, Meijo University, I 50 Yagotoyama, Tenpaku-ku, Nagoya 468-8503, Japan, Tel: +8I 52839 2756, Fax: +8I 52839 2756, E-mail: tnabeshi@ccalumni.meijo-u.ac.jp or Dr K Yamada, Department of Neuropsychopharmacology and Hospital Pharmacy, Graduate School of Medicine, Nagoya University, 65 Tsuruma-cho, Showa-ku, Nagoya 466-8550, Japan, Tel: +8I 52744 2674, Fax: +8I 527442979 , E-mail: kyamada@med.nagoya-u.ac.jp

Received I I March 20 I5; revised 22 May 20 I5; accepted I 3 June 20 I5; accepted article preview online 24 June 2015 homomeric or heteromeric subunit combinations ( $\alpha 2-\alpha 9, \beta 2-$ $\beta 4)$, are widely distributed in the nervous system including fetal brain. The most abundant nAChR subtype is the $\alpha 4 \beta 2$ heteromer in the brain, a homomeric $\alpha 7$ assembly being the other major subtype. Overstimulation of nAChRs by nicotine may have varied developmental influences that are dependent on the pharmacologic properties and localization of the receptors (Dwyer et al, 2008).

In rodents, prenatal nicotine exposure (PNE) has been shown to induce abnormal behaviors such as hyperlocomotion (Zhu et al, 2012) and impairment of emotion (Alkam et al, 2013a), cognitive function (Alkam et al, 2013b), and attention (Schneider et al, 2011). Thus, PNE may bring about long-lasting changes in the brain structure and function of the fetus (Dwyer et al, 2009; Pagani, 2014). In addition, exposure to nicotine during pregnancy from nicotine replacement therapy, as well as active and passive smoking, is becoming an increasingly serious issue worldwide (Pauly and Slotkin, 2008). Despite the identification of fetal exposure to nicotine as a significant risk factor for these and other afflictions of the 
brain, the mechanism underlying PNE-induced brain dysfunction remains obscure.

It is well known that all neurons, astrocytes, and oligodendrocytes, which form the adult nervous system, originate ultimately from progenitor cells located in the ventricular zone (VZ) of the embryonic neural tube. Most neurons in the cerebral cortex are glutamatergic excitatory neurons, and the remainders are GABAergic inhibitory neurons. As cortical development proceeds, these neurons are tightly regulated, dynamically migrate, and form layered structures (Gupta et al, 2002; Marin and Muller, 2014; Tabata et al, 2012) Accordingly, if the formation of the brain layers is affected by an adverse event such as chemical exposure, birth complications, hypoxia, or viral infection during the critical periods of fetal brain development, the exposed offspring may have an increased possibility of suffering from various brain disorders (Herr et al, 2011; Mitsuhashi et al, 2010; Vuillermot et al, 2012).

We have recently demonstrated that PNE, in particular from embryonic day 14 (E14) to postnatal day 0 (P0), impairs cognitive and emotional behaviors (Alkam et al, $2013 a, b)$. In the present study, we investigated the mechanism by which PNE impairs neurodevelopment, resulting in long-lasting behavioral deficits. We have previously analyzed the plasma cotinine levels, a metabolite of nicotine, in dam and pups on the day of delivery, under the same schedule of PNE employed in the present study (Alkam et al, 2013a). The results suggested that PNE under our experimental condition provided similar levels of plasma nicotine in pregnant dams with those found in typical smokers who absorb systemically about $20 \mathrm{mg}$ nicotine daily on the average United States cigarette consumption of 17 cigarettes per day (Matta et al, 2007). With regard to the duration of PNE, we previously examined the effects of pre- and perinatal nicotine exposure in six different time windows including E0-E14, E14-P0, E0-P0, E14-P7, E0-P7, and P0-P7. The most severe behavioral deficits were evident in offspring who exposed to nicotine during the time windows of E14-P0 (Alkam et al, 2013a, b).

In this study, we report that PNE affects the rate of cell cycle progression in neuronal progenitors and consequently impairs cell proliferation via the activation of $\alpha 7 \mathrm{nAChRs}$, leading to the decrease of glutamatergic neurons in the medial prefrontal cortex (medial PFC). Of note, the cognitive deficits induced by PNE are ameliorated by treatment with an $N$-methyl-D-aspartate (NMDA) receptor partial agonist, D-cycloserine (DCS).

\section{MATERIALS AND METHODS}

\section{Animals and Procedure for PNE}

Pregnant dams of C57BL/6J mouse strain on embryonic day 13 (E13) were obtained from Japan SLC (Japan) and were single-housed in plastic cages bedded with sawdust $\left(1 \mathrm{~cm}\right.$ thick) in a regulated environment $\left(24 \pm 1^{\circ} \mathrm{C}\right.$, and $50 \pm 5 \%$ humidity), with a 12 -h light/dark cycle (lights on at 0800 h, off at 2000 h). Food (CE2; Clea Japan, Japan) and tap water were available ad libitum. The day of vaginal plug detection was considered as E0 and the day of birth as postnatal day $0(\mathrm{P} 0)$. All of the experimental procedures described below were in full compliance with the Guidelines for Animal Experiments of Meijo University and NIH guidelines (National Institutes of Health publication 85-23, revised 1996) for the care and use of laboratory animals.

PNE was performed as described previously (Alkam et al, 2013a, b). Briefly, the pregnant mice were given $200 \mu \mathrm{g} / \mathrm{ml}$ nicotine (free base, Sigma, USA) in $2 \%$ sucrose sweetened tap water or $2 \%$ sucrose solution (control) from E14 to P0 (starting at $0900 \mathrm{~h}$ on E14). We have previously demonstrated that the pregnant mice drink $9.31 \pm 0.94 \mathrm{ml} /$ day of $2 \%$ sucrose solution and $5.06 \pm 0.42 \mathrm{ml} /$ day of $200 \mu \mathrm{g} / \mathrm{ml}$ nicotine solution, under the same schedule of PNE in the present study. There was no difference in the number of pups born alive and the sex ratio between control and PNE groups (Alkam et al, 2013b). After weaning on P28, offspring were separated by gender, and then randomly assigned to groups for all experiments to be performed at 8-16 weeks of age. In the experiments described below, age-matched two or three litters were used in each group, and the test was repeated using more than three independent batches to reduce the influence of any litter-related effects on the data.

\section{Determination of Glutamate and GABA by High-Performance Liquid Chromatography}

Each brain sample was weighed and homogenized in methanol containing 3-amino-1-propanesulfonic acid as an internal standard. Following the centrifugation, the sample was derivatized by ortho-phthalaldehyde containing 2-mercaptoethanol and injected into an high-performance liquid chromatography (HPLC) system equipped with a FA-3ODS column (Eicom, Japan) and electrochemical detector (Shen et al, 2014).

\section{In Vivo Microdialysis}

A dialysis probe (D-I-3-01; $1 \mathrm{~mm}$ membrane length; Eicom) was implanted into the PFC (AP: $+1.9 \mathrm{~mm}$; ML: $+0.4 \mathrm{~mm}$ from bregma, DV: $-2.0 \mathrm{~mm}$ from the dura) according to the atlas (Franklin and Paxinos, 2008). Ringer's solution (147 mM $\mathrm{NaCl}, 4 \mathrm{mM} \mathrm{KCl}$, and $2.3 \mathrm{mM} \mathrm{CaCl}_{2}$ ) was continuously perfused $(1.0 \mu \mathrm{l} / \mathrm{min})$ starting 2 days after implantation of the dialysis probe. The dialysates were collected every $10 \mathrm{~min}$ and analyzed by HPLC. Six samples were taken to establish the baseline level of extracellular glutamate. For depolarization stimulation, Ringer's solution containing $50 \mathrm{mM} \mathrm{KCl}$ was delivered through the dialysis probe for $20 \mathrm{~min}$ to measure the $\mathrm{K}^{+}$-evoked release of glutamate (Murai et al, 2007).

\section{5-Bromo-2'-Deoxyuridine Injection Schedules}

Pregnant mice were injected intraperitoneally with $50 \mathrm{mg} / \mathrm{kg}$ 5-bromo-2'-deoxyuridine (BrdU; Sigma) in saline (SAL).

Migration assay (laminar fate of progenitor cells). For labeling neural progenitors cycling through the S-phase in E13 embryos, pregnant mice were injected with BrdU (at $1500 \mathrm{~h}$ on E13) $18 \mathrm{~h}$ before nicotine exposure (starting at $0900 \mathrm{~h}$ on E14). A single injection of BrdU was given on E14, $\mathrm{E} 15$, or E16 (each at $1500 \mathrm{~h}$ ) during nicotine exposure. Brains were collected on P7 or postnatal week 8-10 (adult) (Toriumi et al, 2012). 
Cumulative BrdU labeling. To determine the effect of nicotine on the overall length of the cell cycle $\left(T_{\mathrm{c}}\right)$, the length of S-phase $\left(T_{\mathrm{S}}\right)$, and the proportion of cells that were actively cycling, ie, the growth fraction (GF), we performed cumulative BrdU labeling in E14 embryos by giving pregnant mice repeated injections of BrdU (at $2 \mathrm{~h}$ intervals over a period of $20.5 \mathrm{~h}$ ), simultaneous with the start of nicotine exposure, based on published methods (Fukumitsu et al, 2006). The last BrdU injection was given $30 \mathrm{~min}$ before decapitation (see Supplementary Figure S2A). For estimating the total cell number, cell nuclei were stained with propidium iodide (PI) (Invitrogen, Carlsbad, CA, USA). A labeling index (LI) was expressed as the ratio of area of $\mathrm{BrdU}^{+} / \mathrm{PI}^{+}$ cells per area of total cells $\left(\mathrm{PI}^{+}\right.$cells) in $\mathrm{VZ}$ and subventricular zone (SVZ). Area of total cells in VZ and SVZ was defined between the lateral ventricle and the pial surface, and measured by the imaging software (Dynamic cell count BZ-H1C; KEYENCE, Japan). The maximum LI or GF is attained when all of the cycling cells have passed into S-phase.

\section{Preparation of Brain Slices and Staining}

Adult offspring were anesthetized with urethane and perfused transcardially with ice-cold phosphate-buffered saline (PBS), followed by $4 \%$ paraformaldehyde in PBS. After cryoprotection in $30 \%(\mathrm{w} / \mathrm{v})$ sucrose, coronal sections $20 \mu \mathrm{m}$ thick were cut with a cryostat (Micro-edge Instruments, Japan). Embryonic brains were cut $8 \mu \mathrm{m}$ thick (Aoyama et al, 2014).

For immunohistochemical staining, the sections were incubated in $100 \%$ methanol for $30 \mathrm{~min}$ and permeabilized with $0.1 \%$ Triton $\mathrm{X}-100$ in $0.1 \mathrm{M}$ Tris- $\mathrm{HCl}$ for $30 \mathrm{~min}$ at $37^{\circ} \mathrm{C}$, and then subjected to antigen retrieval by antigen unmasking solution (Vector Labs, Burlingame, CA, USA) at $100^{\circ} \mathrm{C}$ for $2 \mathrm{~min}$. The primary antibodies used were as follows: anti-GLS (1:250; Abcam), anti-NeuN (1:2000; Millipore), anti-BrdU ( $1: 10$; from BrdU Labeling and Detection Kit, Roche), antiPax6 (1:500; MBL), anti-proliferation cell nuclear antigen (PCNA) (1:5000; Dako), and anti-Tbr2 (1:500; Abcam) antibodies. Fluorescently conjugated secondary antibodies (Alexa Fluor 488 and 546; Invitrogen) were used. Terminal deoxynucleotidyl transferase-mediated dUTP-biotin nick-end labeling (TUNEL) staining was performed according to the manufacturer's instructions (Roche).

\section{Image Acquisition and Analysis}

Brain section images were acquired with a confocal microscope (LSM510; Carl Zeiss, Jena, Germany) or a light microscope (Biorevo BZ-9000; KEYENCE), and the number of immune-positive cells was measured in a region of interest by the imaging software WinRoof (Mitani, Japan). Immunepositive cells were counted in either the right or left hemispheres of at least three different sections for each brain area. The cell counts were performed within a rectangular grid of known area that encompassed each zone of the cerebral wall so that the number of immune-positive cells could be expressed as the number per unit area for each zone. The average of these determinations for each section was defined as the number of immune-positive cells within a specified area in the individual brain. The average of these values for the individual brain was used for statistical analysis. This procedure was performed by an individual blinded to the treatment conditions (Niwa et al, 2010; Penagarikano et al, 2011).

\section{Behavioral Analysis}

All behavioral tests were performed between 1000 and $1800 \mathrm{~h}$. Behavioral experiments were performed in a soundattenuated and air-regulated experimental room, in which mice were habituated for more than $1 \mathrm{~h}$. Methods for the object-based attention test (Alkam et al, 2011), the marbleburying behavior test (Njung'e and Handley, 1991), the elevated plus-maze test (Pellow et al, 1985), the fear conditioning test (Kaczorowski et al, 2012; Morgan et al, 1993) and the latent inhibition test (Moser et al, 2000) are provided in the Supplementary information section. Mice were administered DCS (30 mg/kg, s.c.; Sigma), dissolved in SAL, $30 \mathrm{~min}$ before the beginning of the following behavioral experiments. For microinfusion, mice were bilaterally implanted with a guide cannula in the PFC $\left(15^{\circ}\right.$ angle from AP: $+1.7 \mathrm{~mm}$; ML: $\pm 1.0 \mathrm{~mm}$ from Bregma, DV: $-1.5 \mathrm{~mm}$ from the dura). DCS ( $5 \mathrm{nmol}$ per $0.5 \mu \mathrm{l} /$ bilaterally) was injected into each PFC through an infusion cannula (6.0 mm, $0.35 \mathrm{~mm}$ in diameter; Eicom), which was connected to a microsyringe mounted on an infusion pump 10 min before the behavioral test. The doses of DCS for systemic administration and microinjection were determined according to the previous reports (Murai et al, 2007; Yamada et al, 2009).

\section{Statistical Analysis}

All data except for the cell cycle kinetics data were expressed as the mean \pm SEM. The difference among three or more groups was analyzed for statistical significance by one-way, two-way, or two-way repeated-measures analysis of variance (ANOVA), followed by Bonferroni's multiplecomparison test. Statistical significance of differences between two groups was determined with Student's $t$-test. A $P<0.05$ was regarded as statistically significant. Cell cycle parameters with 95\% confidence limits were calculated using a liner fit procedure (Prism 5; GraphPad Software, San Diego, CA, USA). A significant difference in cell cycle parameters was obtained when comparisons presented non-overlapping 95\% limits.

\section{RESULTS}

\section{PNE Reduced the Density of Glutamatergic Neurons in the Medial PFC}

To explore the possible cause of behavioral deficits in mice with PNE (PNE mice), we first measured glutamate content in the frontal cortex of adult PNE mice. Glutamate content in the frontal cortex was significantly lower in PNE mice than control mice, while there was no difference in GABA content between the two groups (Figure 1a: $P<0.01$ by Student's $t$-test). In other brain regions such as the nucleus accumbens, striatum, hippocampus, amygdala, and cerebellum, glutamate and GABA contents were not significantly different between the control and the PNE mice (Supplementary 

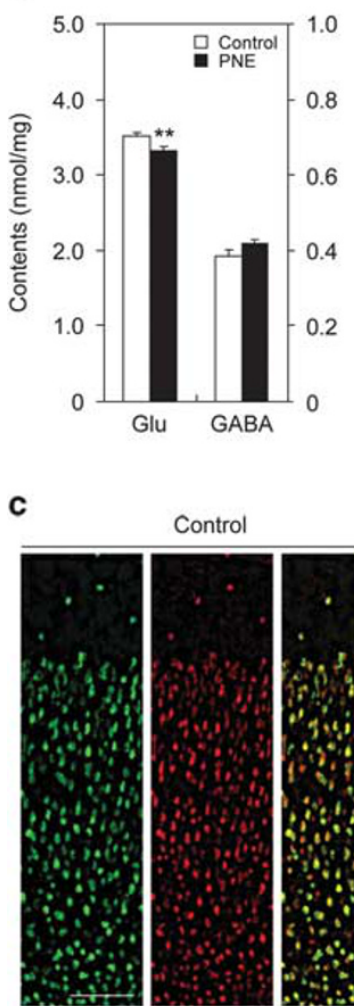

NeuN

Control b
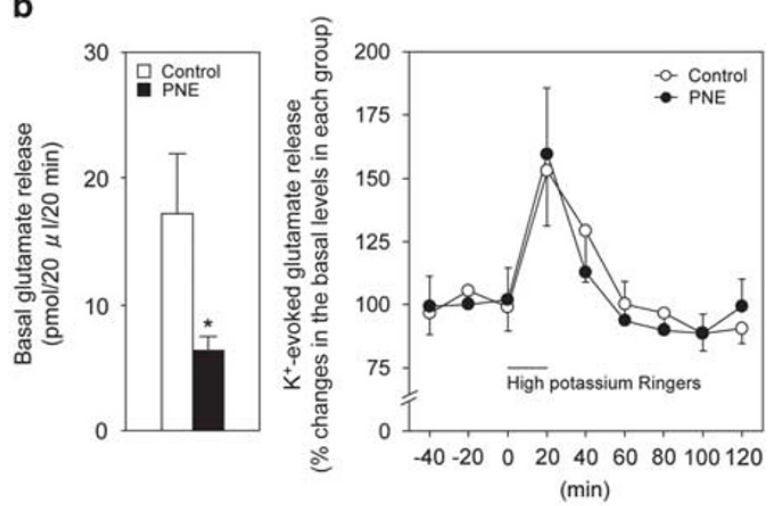

PNE

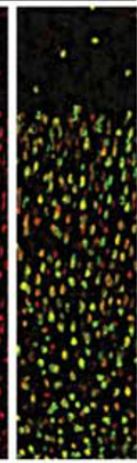

GLS2 NeuN/GLS2

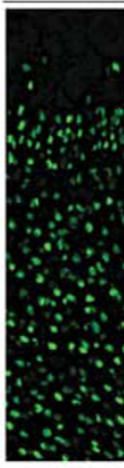

Neun
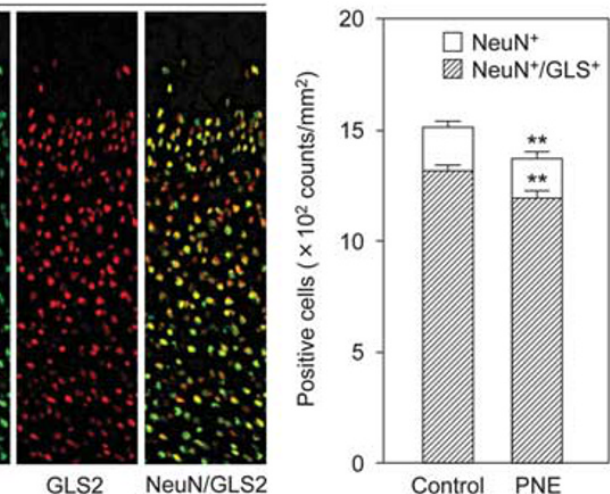

Figure I PNE reduced the density of glutamatergic neurons in the medial PFC. (a) Glutamate and GABA contents in the frontal cortex of control $(n=\mid 4$ at the age 10-12 weeks consists of seven males and seven females) and PNE prenatal nicotine exposure mice $(n=12$ at the age $10-12$ weeks consists of five males and seven females). (b) Basal extracellular glutamate level and the high potassium (50 mM) stimulation-evoked glutamate release were measured in the PFC of control ( $n=8$ at the age 12-16 weeks consists of four males and four females) and PNE mice ( $n=8$ at the age $12-16$ weeks consists of four males and four females). (c) NeuN- and GLS-immunostained coronal sections of the medial PFC in control and PNE mice. Quantitative analysis of the density of NeuN- and NeuN/GLS-stained cells was shown ( $n=1$ I for control mice at the age I0-12 weeks consists of four males and seven females, $n=1 \mid$ for PNE mice at the age 10-12 weeks consists of four males and seven females). Values are the means \pm SEM. $* P<0.05$, **P $<0.01$ vs corresponding control mice Scale bar: $100 \mu \mathrm{m}$.

Table S1). To further investigate glutamatergic function in PNE mice, depolarization-evoked glutamate release in the PFC was investigated by microdialysis. The basal level of extracellular glutamate in the PFC was significantly lower in PNE mice than control mice, but there was no difference between the two groups in the response to potassium $(50 \mathrm{mM})$ stimulation (Figure 1b: basal glutamate levels, $P<0.05$ by Student's $t$-test; depolarization-evoked glutamate release, two-way repeated-measures ANOVA, $F_{\text {group }}(1,14)=$ $0.0054, P=0.94 ; F_{\text {time }}(6,84)=7.77, P<0.01 ; F_{\text {interaction }(6,84)}=$ $0.28, P=0.94)$. Next, we checked the density of glutamatergic neurons in the medial PFC of PNE mice by immunohistochemical analysis. GLS2 was used as a glutamatergic neuronal marker, because it is detected only in pyramidal neurons, and not in GABA-immunoreactive neurons or in nonpyramidal neurons (Kaneko and Mizuno, 1994). Glutamatergic neurons $\left(\mathrm{NeuN}^{+} / \mathrm{GLS}^{+}\right)$, among neuronal cells $\left(\mathrm{NeuN}^{+}\right)$, was significantly decreased in PNE mice compared with control mice (Figure 1c: $P<0.01$ by Student's $t$-test). These results suggest that PNE may impair neurogenesis in especially glutamatergic neuron, resulting in hypoglutamatergic function in the medial PFC in adulthood.

\section{PNE Impaired Neurogenesis but not Neuronal Migration}

Glutamatergic pyramidal neurons in the cerebral cortex, generated in the cortical $\mathrm{VZ}$ and SVZ, migrate radially to their appropriate position, resulting in the formation of the cortical layers in an inside-out manner (Dehay and Kennedy, 2007). It has been reported that defect of neuronal migration is associated with the reduction of neuronal cells in mice (Penagarikano et al, 2011). If neural migration was impaired by PNE, the ectopic distribution of neurons might lead to a decrease in the density of glutamatergic neurons in the medial PFC. To verify this possibility, we performed a migration assay using BrdU, which is incorporated into newly synthesized DNA and therefore labeling newborn cells at the time of injection. Pregnant mice were injected with BrdU once either on E13, E14, E15, or E16, and the BrdU ${ }^{+}$ cells in the brains of offspring were counted on P7 (Figure $2 \mathrm{a}$ ) or in adulthood (8-10 weeks old) (Figure 2b). The BrdU ${ }^{+}$cells distributed normally in the medial PFC with an inside-out pattern, and there were no apparent differences between the control and PNE mice (two-way repeatedmeasures ANOVA). However, the density of $\mathrm{BrdU}^{+}$cells labeled on E14, E15, and E16 was significantly decreased by 
a

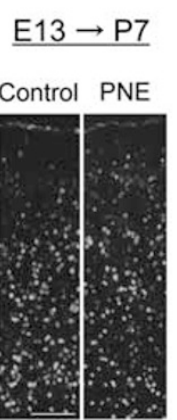

Cell Number (\%)

$\underline{E} 14 \rightarrow \mathrm{P} 7$

$\begin{array}{llll}0 & 10 & 20 & 30 \\ \text { Control PNE }\end{array}$

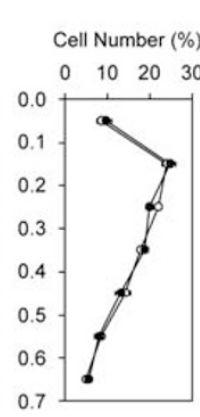

$\underline{\mathrm{E} 15 \rightarrow \mathrm{P} 7}$

Cell Number $(\%)$

$\underline{E} 16 \rightarrow \mathrm{P} 7$

$\begin{array}{llll}20 & 40 & 60 & \text { Control PNE }\end{array}$
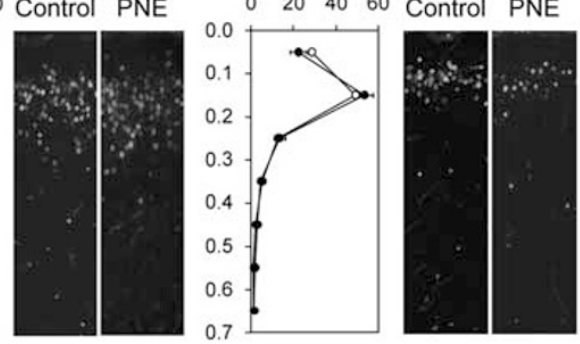

Cell Number $(\%)$

$0 \quad 20 \quad 40 \quad 60$
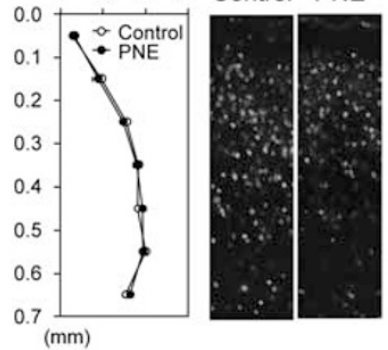

7

E16 $\rightarrow$ Adult

Cell Number (\%)

b $_{\text {E14 } \rightarrow \text { Adult }}$

Cell Number $(\%)$ Control PNE 020406080
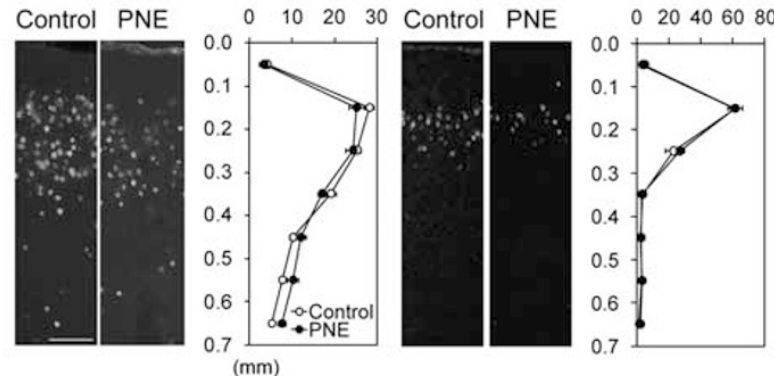

C
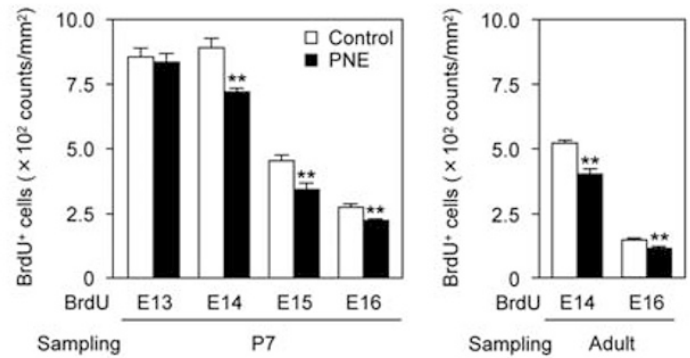

d
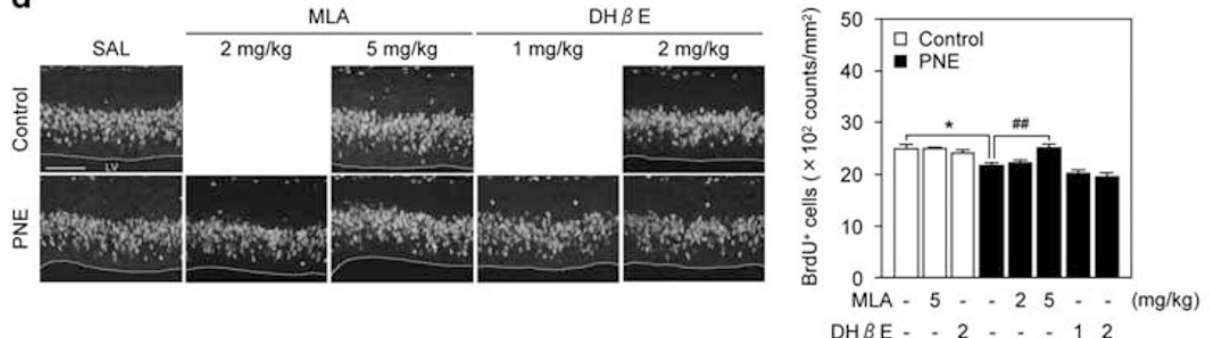

Figure 2 PNE impaired neurogenesis but not neuronal migration. (a, b) PNE did not affect laminar destination of cells generated on EI3-EI6 in the P7 or adult. Fluorescence images of $\mathrm{BrdU}^{+}$cells and distribution of $\mathrm{BrdU}^{+}$cells, labeled on EI3-EI6, in the medial PFC of control and PNE mice at each distance from the pial surface are shown ( $n=6-8$ for control mice consists of 3-5 males and 3-4 females, $n=6-8$ for PNE mice consists of 3-5 males and 3-4 females). To label mitotic progenitors in the embryonic brains, the pregnant mice were given a single BrdU injection on EI3, EI4, EI5, or EI6, and then their offspring brains were collected on (a) postnatal day 7 or (b) adult at the age 8-10 weeks. (c) Quantitative analysis of the density of BrdU ${ }^{+}$cells is shown ( $n=6-8$ for control mice consists of 3-5 males and 3-4 females, $n=6-8$ for PNE mice consists of 3-5 males and 3-4 females). $* * P<0.01$ vs corresponding control mice. (d) Reduction of $\mathrm{BrdU}^{+}$cells in the proliferative zones that migrate to form the medial PFC of PNE mice was blocked by nAChRs $\alpha 7$ antagonist, but not $\alpha 4 \beta 2$ antagonist. Pregnant mice were given a single BrdU injection 15 min after pretreatment with MLA or DH $\beta E$ on EI4, and then were killed 30 min later. Fluorescence images of BrdU ${ }^{+}$cells in the proliferative zones that migrate to form the medial PFC are shown. Quantitative analysis of the density of $\mathrm{BrdU}^{+}$cells in control and PNE mice pretreated with MLA or DH $\beta E$ are shown ( $n=3-6$ for control mice, $n=6-8$ for prenatal nicotine exposure mice). Values are the means \pm SEM of at least three independent experiments. ${ }^{*} P<0.05$ vs SAL-treated control mice, ${ }^{\# \#} P<0.0$ I vs SAL-treated PNE mice. LV: lateral ventricle. Scale bar: $100 \mu \mathrm{m}$.

PNE on P7, and the changes persisted until adulthood (Figure 2c: $P<0.01$ by Student's $t$-test). PNE-induced decrease in $\mathrm{BrdU}^{+}$cells on E14 was evident 30 min after $\mathrm{BrdU}$ administration in the proliferative zones (Figure $2 \mathrm{~d}$ ), and was attenuated by pretreatment with $5 \mathrm{mg} / \mathrm{kg}$ methyllycaconitine (MLA), a nAChR $\alpha 7$ antagonist, but not dihidro$\beta$-erythroidine (DH $\beta E$ ), a $\mathrm{nAChR} \quad \alpha 4 \beta 2$ antagonist (Figure 2d: one-way ANOVA, $F(7,40)=12.72, P<0.01)$ ). At this time, TUNEL $^{+}$cells were not observed in the medial PFC from the E14 control and PNE embryos (Supplementary Figure S1). These results suggest that $\alpha 7 \mathrm{nAChRs}$ mediate decreased proliferation of neuronal progenitors in the VZ and SVZ layers by PNE. It is less likely that apoptosis is induced by PNE treatment. Because neither MLA nor DH $\beta E$ affected BrdU labeling in control mice, it is suggested that activation of $\alpha 4 \beta 2$ and $\alpha 7 \mathrm{nAChRs}$ by endogenous ACh has little effects on mitosis of neuronal progenitors and BrdU transport to fetal brain under control condition.

\section{PNE Reduced the Density of Neuronal Progenitors in the VZ and SVZ}

Three main types of cortical neuronal progenitors have been identified to be involved in corticogenesis: radial glial cells, short neural precursors, and intermediate progenitor cells (Dehay and Kennedy, 2007). Both the short neural 


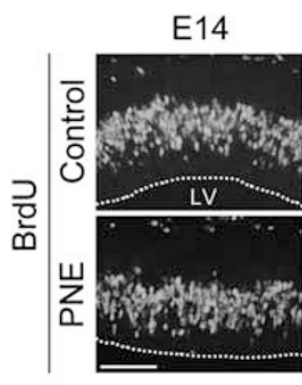

E16
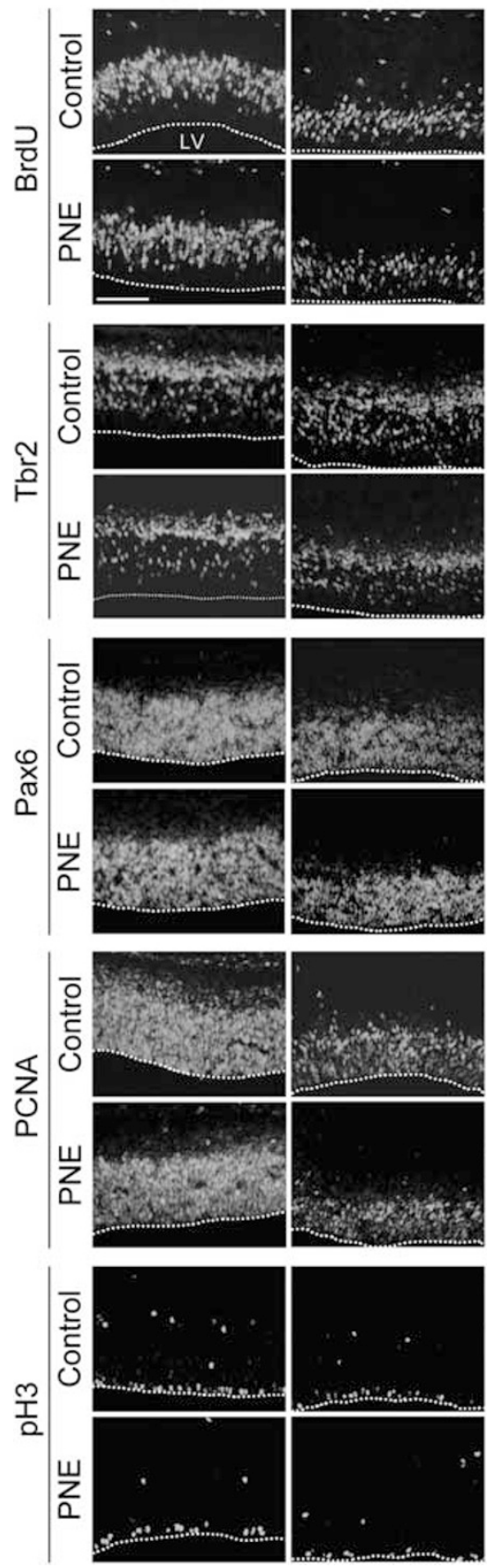

E18
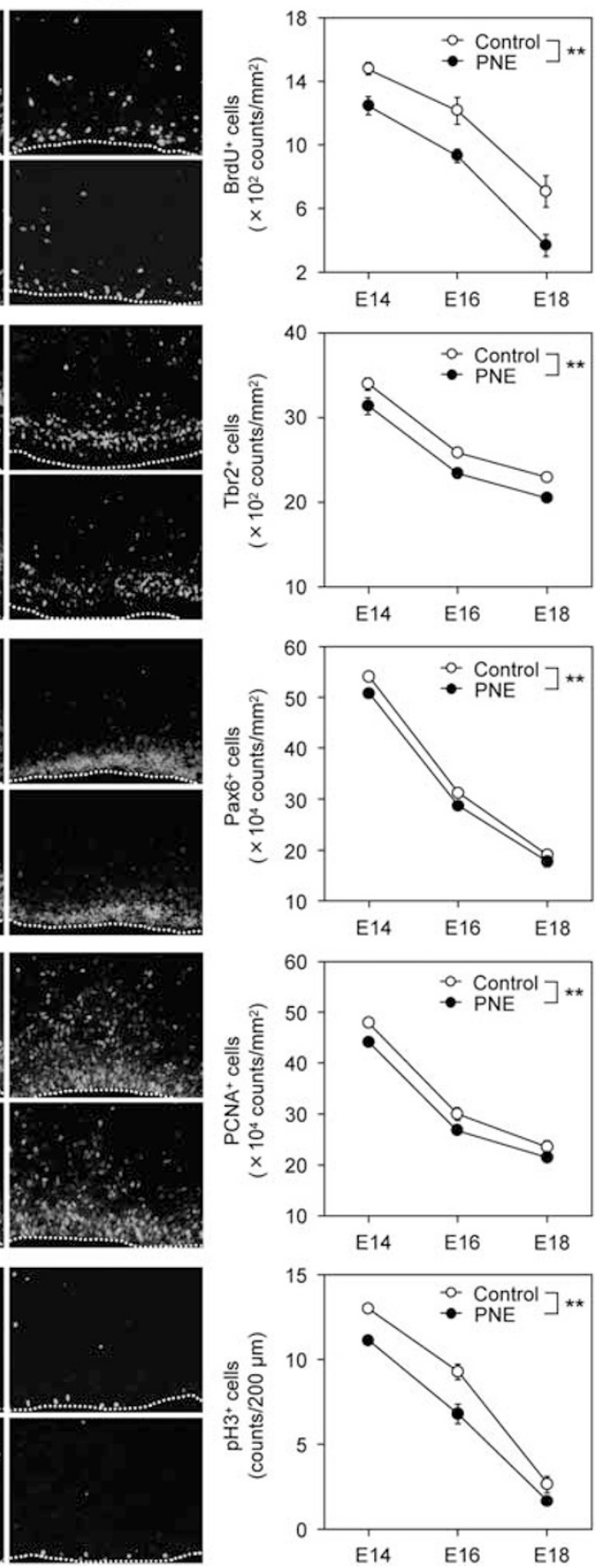

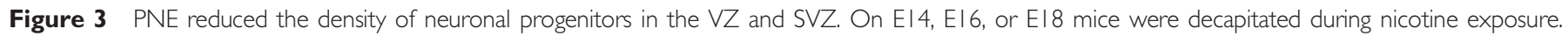

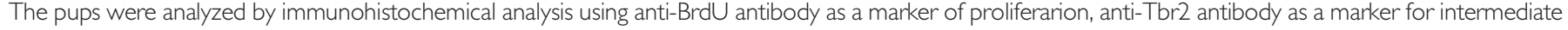

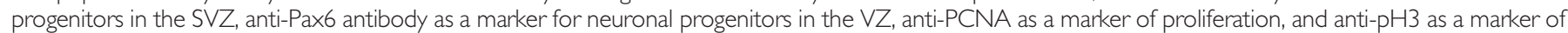

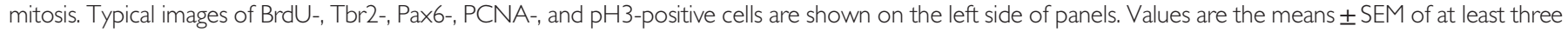
independent experiments ( $n=6-7$ for control mice, $n=6-7$ for PNE mice). *** $<0.0$ I vs control mice. LV: lateral ventricle. Scale bar: I00 $\mu$ m.

precursors and radial glia divide at the ventricular surface and express the transcription factor, Pax6. On the other hand, the intermediate progenitor cells divide away from the ventricular surface and are located in the SVZ, and express the transcription factor, Tbr2. Pax6 and Tbr2 are expressed sequentially in the neurogenesis of glutamatergic neurons (Englund et al, 2005). To investigate whether stimulation of nAChRs affects the neuronal precursor pool for neurogenesis, we estimated the number of these neural progenitors in the VZ and SVZ. The number of $\mathrm{BrdU}^{+}, \mathrm{Tbr}^{+}$, and $\mathrm{Pax}^{+}$ cells in control mice progressively decreased as the gestation period increased from E14 to E18. The gestation periodassociated decrease in the number of progenitors was significantly facilitated by PNE, especially for $\mathrm{BrdU}^{+}$cells. Likewise, $\mathrm{Tbr}^{+}$basal progenitors and $\mathrm{Pax}^{+}{ }^{+}$neural progenitors were significantly decreased in PNE mice in comparison with control mice (Figure 3: $\mathrm{BrdU}, F_{\text {group }}(1,30)=26.50$, $P<0.01 ; F_{\text {age }}(2,30)=76.65, P<0.01 ; F_{\text {interaction }}(2,30)=0.32$, $P=0.73 ;$ Tbr2, $F_{\text {group }}(1,36)=25.56, P<0.01 ; \quad F_{\text {age }}(2,36)=$ 174.87, $P<0.01 ; \quad F_{\text {interaction }(2,36)}=0.0080, P=0.99 ;$ Pax6, 
Table I Cell Cycle Parameters (h) of Cortical Progenitors in Control and PNE Embryos

Cell cycle parameters $(h)$

\begin{tabular}{|c|c|c|c|c|}
\hline & $T_{c}-T_{s}(95 \% \mathrm{Cl})$ & $T_{\mathrm{s}}(95 \% \mathrm{Cl})$ & $T_{c}(95 \% \mathrm{Cl})$ & GF (\%) $( \pm$ SEM $)$ \\
\hline PNE & $12.29(11.29-13.69)$ & $8.9 \mid(6.50-12.36)$ & $22.37(20.19-23.65)$ & $71.42 \pm 1.97$ \\
\hline
\end{tabular}

Abbreviations: $\mathrm{Cl}$, confidence interval; GF, growth fraction; PNE, prenatal nicotine exposure; $T_{c}$, total length of the cell cycle; $T_{\mathrm{s}}$, length of the S-phase.

These values are determined by calculating from the regression lines indicated in Supplementary Figure S2B. Ts is given by the projection of LI $=0$ on the $x$ axis ( $x$-intercept). The projection of the maximum $L I=G F$ onto the $x$ axis gives $T_{c}-T_{s}$.

$F_{\text {group }(1,30)}=15.28, P<0.01 ; F_{\text {age }(2,30)}=906.83, P<0.01$; and $\left.F_{\text {interaction }(2,30)}=0.87, P=0.43\right)$. Furthermore, $\mathrm{PCNA}^{+}$and $\mathrm{pH}^{+}$(a proliferative cell marker and a mitosis cell marker, respectively) cells were also significantly decreased as a function of gestation period in control mice, and the effect was facilitated by PNE (Figure 3: PCNA, $F_{\text {group }}(1,36)=$ $15.80, P<0.01 ; F_{\text {age }}(2,36)=365.70, P<0.01 ; F_{\text {interaction }(2,36)}=$ $0.13, \quad P=0.88 ; \quad \mathrm{pH} 3, \quad F_{\text {group }}(1,30)=29.30, \quad P<0.01$; $\left.F_{\text {age }(2,30)}=284.96, P<0.01 ; F_{\text {interaction }(2,30)}=1.80, P=0.18\right)$. These results suggest that PNE facilitates the gestation period-dependent downregulation of neural progenitors, which may lead to the decrease in glutamatergic neurons in the medial PFC.

\section{PNE Disrupted the Cell Cycle in Neuronal Progenitors}

To further explore the reason underlying the decrease in proliferation of neural progenitors in PNE mice, the cell cycle length of E14 cortical progenitors in PNE mice was determined by cumulative BrdU labeling (Supplementary Figure S2 and Table 1). The regression lines and coefficients obtained from the linear fit were significantly different between the control and PNE mice (Supplementary Figure S2B: slope, $F_{\text {group }}(1,5)=1.49, \quad P=0.28$; $F_{\text {time }(1,5)}=589.69, P<0.01 ; F_{\text {interaction }(1,5)}=14.81, P<0.05$; intercept, $F_{\text {group }}(1,6)=10.52, P<0.05 ; \quad F_{\text {time }}(1,6)=180.30$, $P<0.01)$. Cumulative BrdU labeling of the E14 cortex revealed that the total cell cycle length $\left(T_{\mathrm{c}}\right)$ of the cortical progenitors was significantly longer in PNE mice $(22.37 \mathrm{~h}$, 95\% confidence interval (CI): 20.19-23.65 h) than control mice $(15.38 \mathrm{~h}, 95 \% \mathrm{CI}: 14.50-18.25 \mathrm{~h})$. This was partly caused by elongation of the S-phase (Table 1). These observations suggested that PNE disrupted cell cycle kinetics of progenitors, leading to impairment of proliferation.

\section{PNE-induced Cognitive Deficits were Ameliorated by Treatment with DCS in Adulthood}

Finally, we investigated whether activation of glutamatergic neurotransmission ameliorates behavioral deficits induced by PNE. In the LI test to investigate the effects of PNE on attentional shifting and cognitive flexibility (Labrie et al, 2010; Vuillermot et al, 2012), PNE mice exhibited normal LI response as did control mice under a 2CS-US protocol (data not shown). An increase in conditioning trials from the 2CSUS to 4CS-US protocol abolished LI in control mice, whereas LI continued to be present in PNE mice (Figure 4a: two-way repeated-measures ANOVA, $F_{\text {group }}(3,38)=12.09, P<0.01$; $\left.F_{\text {time }(2,76)}=115.35, P<0.01 ; F_{\text {interaction }(6,76)}=3.71, P<0.01\right)$.
In the auditory fear conditioning test (Figure 4b), PNE did not affect the acquisition (day 1) or expression and extinction (day 2) of the learned fear response to the tone. However, in the following recall phase (day 3), PNE mice showed higher levels of freezing than control mice (Figure 4b: day 3 (recall phase), two-way repeated-measures ANOVA, $F_{\text {group }(3,45)}=56.50, P<0.01 ; F_{\text {trial }}(2,90)=19.39$, $\left.P<0.01 ; F_{\text {interaction }(6,90)}=1.21, P=0.31\right)$. Sensitivity to foot shock, which served as the aversive stimulus, were indistinguishable (control mice: $56.1 \pm 3.9 \mu \mathrm{A}, n=28$; PNE mice: $53.0 \pm 3.4 \mu \mathrm{A}, n=30 ; P=0.55$ by Student's $t$-test). Several reports have suggested that glutamatergic malfunction in the PFC has an important role in cognitive and attentional deficits in the above-mentioned behavioral experiments (Arnsten et al, 2010; Burgos-Robles et al, 2007; Labrie et al, 2010). To verify this possibility, we examined whether the facilitation of glutamatergic neurotransmission by the NMDA receptor partial agonist, DCS, was able to improve the behavioral deficits induced by PNE. Systemic administration of DCS $(30 \mathrm{mg} / \mathrm{kg}$, s.c.) ameliorated the attentional deficits in PNE mice in the object-based attention test (Figure 4c: exploratory preference in the retention session, two-way ANOVA, $F_{\text {group }}(1,64)=18.90, P<0.01$; $F_{\text {treatment }} \quad(1,64)=12.34, \quad P<0.01 ; \quad F_{\text {interaction }}(1,64)=16.32$, $P<0.01)$ and anxiety-like behavior in the marble burying (Figure 4d: two-way ANOVA, $F_{\text {group }(1,64)}=3.56, P=0.064$; $F_{\text {treatment }} \quad(1,64)=2.02, \quad P=0.16 ; \quad F_{\text {interaction }}(1,64)=7.57$, $P<0.01$ ) and elevated plus-maze tests (Figure 4e: open arm entries, two-way ANOVA, $F_{\text {group }}(1,64)=7.98, P<0.01$; $F_{\text {treatment }} \quad(1,64)=6.35, \quad P<0.05 ; \quad F_{\text {interaction }} \quad(1,64)=2.57$, $P=0.11)$. Furthermore, to test if hypoglutamatergic function in the PFC had a crucial role in the behavioral abnormalities induced by PNE, PNE mice received bilateral microinjections of DCS into the PFC 10 min before the extinction session of the auditory fear conditioning test. DCS-treated PNE mice showed a significantly attenuated freezing behavior in the recall phase, compared with SAL-treated PNE mice (Figure 4f: day 3 (recall phase), two-way repeatedmeasures ANOVA, $F_{\text {group }(3,39)}=7.09, P<0.01 ; F_{\text {trial }}(2,78)=$ $\left.21.04, P<0.01 ; F_{\text {interaction }(6,78)}=0.54, P=0.78\right)$, despite both groups of mice exhibiting similar extinction behavior on day 2 (Figure 4f). The DCS microinjections into the PFC had little effect on the anxiety-like behavior in PNE mice in the elevated plus-maze test (Figure 4g: open arm entries, twoway ANOVA, $F_{\text {group }(1,39)}=22.04, P<0.01 ; F_{\text {treatment }(1,39)}=$ $\left.1.10, P=0.30 ; F_{\text {interaction }(1,39)}=1.21, P=0.28\right)$, while systemic treatment with DCS ameliorated it (Figure 4e). These results suggest that glutamatergic dysfunction in the PFC may 
a

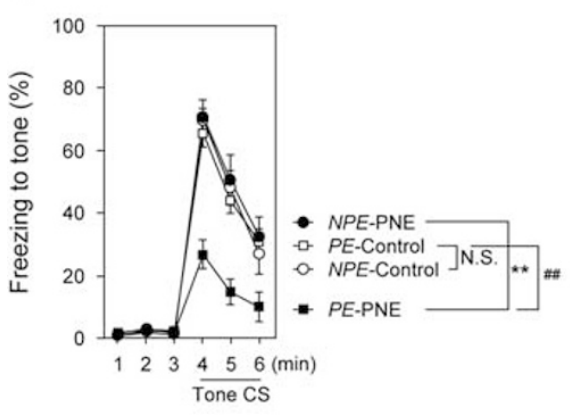

b

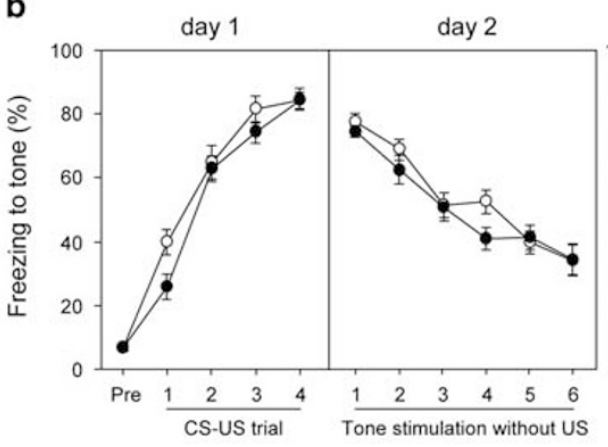

day 3

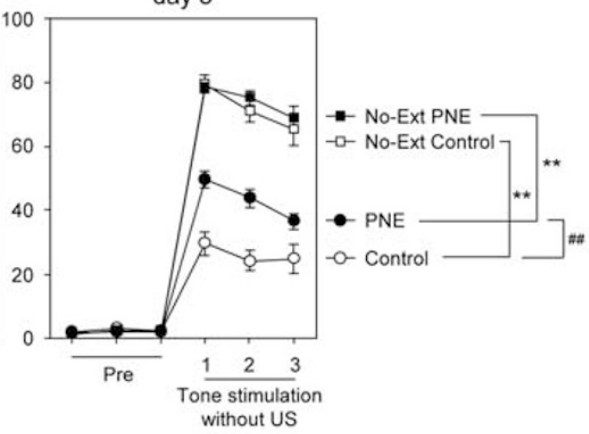

C

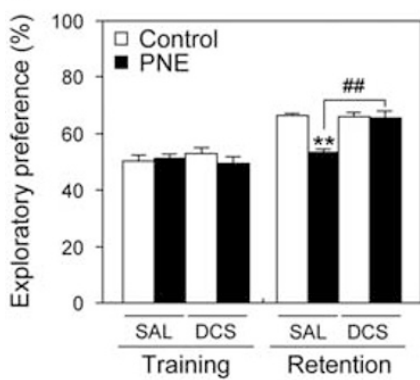

e
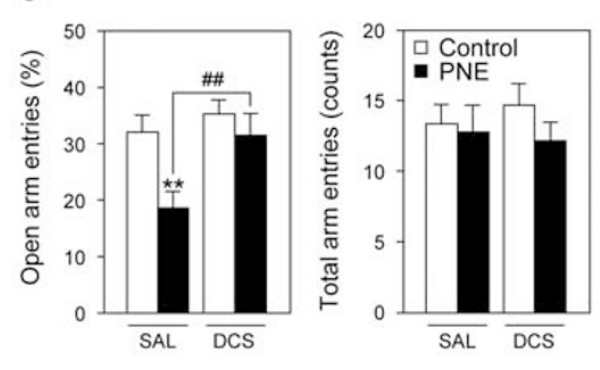

f

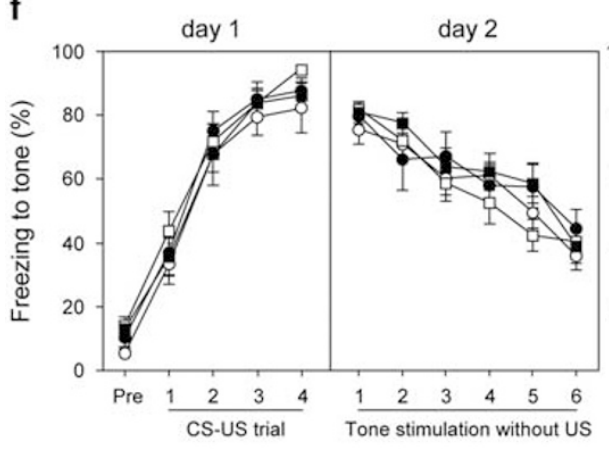

d

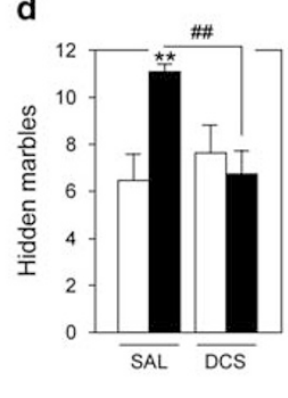

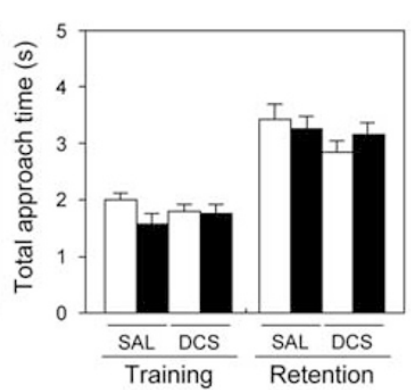

day 3

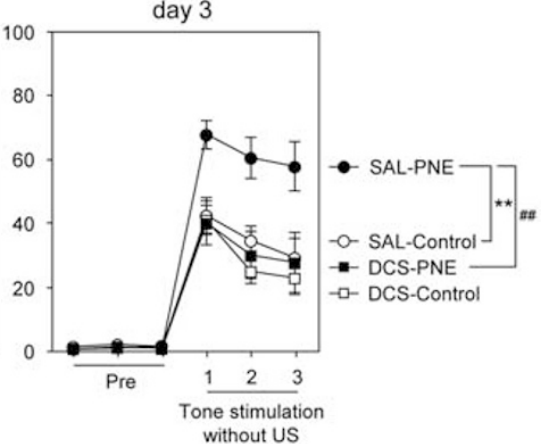

g

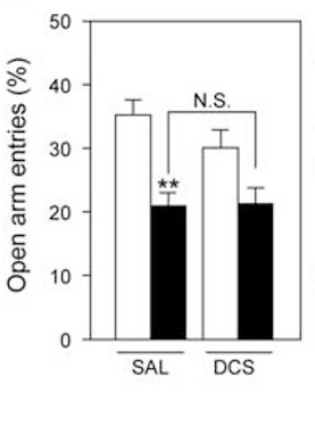

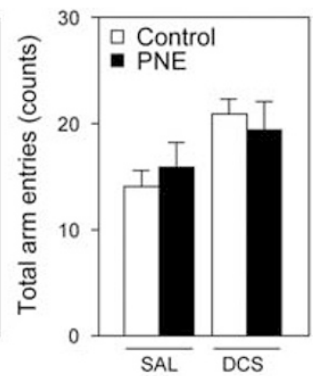

Figure 4 PNE-induced cognitive deficits were ameliorated by treatment with DCS in adulthood. (a, b) PNE mice exhibited cognitive deficits in the latent inhibition and fear conditioning tests in adulthood. (a) Freezing to tone under a 4CS-US protocol in the latent inhibition test was measured $24 \mathrm{~h}$ after the conditioning ( $n=10$ for control mice at the age 10-12 weeks consists of four males and six females, $n=1 \mid$ for PNE mice at the age I0-12 weeks consists of four males and seven females). ${ }^{*} P P<0.01$ vs corresponding NPE group, ${ }^{\# \#} P<0.01$ vs PE-control group. (b) Freezing to tone in the conditioning (day I), extinction (day 2), and recall (day 3 ) phases were measured in the fear conditioning test ( $n=7-16$ for control mice at the age $10-12$ weeks consists of 5-8 males and 2-8 females, $n=9-17$ for PNE mice at the age 10-12 weeks consists of $7-10$ males and $2-7$ females). $* * *<0.01$ vs corresponding groups, ${ }^{\# \#} P<0.01$ vs control group. ( $\left.c-e\right)$ Systemic administration of DCS ameliorated behavioral deficits in PNE mice $(n=18$ for control mice at the age $10-$ 14 weeks consists of 6-9 males and 9-12 females, $n=16$ for PNE mice at the age $10-14$ weeks consists of $8-10$ males and 6-8 females). DCS (30 mg/kg, s.c.) was administered to the PNE mice 30 min before these behavioral experiments. (c) Object-based attention test. Exploratory preference (left side panel) and total approach time (right side panel) were measured during a 3-min session. (d) Marble-burying test. Hidden marbles were counted during a I5-min session. (e) Elevated plus-maze test. Open arm entries (left side panel) and total arm entries (right side panel) were measured during a 5-min session. *** $<0.0$ I vs SAL-treated control mice, ${ }^{\#} P<0.01$ vs SAL-treated PNE mice. (f, g) Microinjections of DCS into the PFC ameliorated cognitive deficits but had little effect on the anxiety-like behavior in PNE mice ( $n=11-12$ for control mice at the age $12-16$ weeks consists of 5-6 males and six females, $n=10$ for PNE mice at the age 12-16 weeks consists of five males and five females). (f) In the fear conditioning test, DCS ( $5 \mathrm{nmol}$ per $0.5 \mu / / \mathrm{bilaterally)}$ was injected 10 min before the extinction trials. (g) In the elevated plus-maze test, DCS ( $5 \mathrm{nmol}$ per $0.5 \mu$ l/bilaterally) was injected mice 10 min before the beginning of the test. $* * *<<0.0$ I vs SAL-treated control mice, ${ }^{\#} P<0.01$ vs SAL-treated PNE mice. Values are the means \pm SEM. Abbreviations: CS, conditioned stimulus; No-Ext, Noextinction; NPE, non-pre-exposed; N.S., not significant; PE, pre-exposed; US, unconditioned stimulus.

contribute to cognitive deficits but not other emotional alterations in PNE mice.

\section{DISCUSSION}

In the developing brain, nAChRs have been implicated in neuronal proliferation, apoptosis, migration, and differentiation (Dwyer et al, 2008, 2009). Accordingly, nicotine is likely to affect these processes during neurodevelopment, depending on the dose, developmental stage, and tissue or cell type. In fact, many studies have demonstrated that nicotine exposure affects neuronal proliferation, apoptosis, migration, and differentiation in progenitor cells (He et al, 2013; Shingo and Kito, 2005; Takarada et al, 2012). 
For instance, Takarada et al (2012) demonstrated that in undifferentiated neural progenitors, continuous exposure to nicotine led to a significant decrease in the capability to form neurospheres and subsequently accelerated neuronal differentiation. Another study showed that chronic administration of nicotine inhibited hippocampal neurogenesis in vivo, but had little effect on the differentiation of neuronal progenitors (Shingo and Kito, 2005). In a recent study, PNE was reported to reduce the cingulate cortex volume in mice (Zhu et al, 2012), as observed in $\mathrm{AD} / \mathrm{HD}$ subjects (Makris et al, 2010), implying that the reduced thickness of cortical layers may be associated with the decrease in cell number induced by PNE. In addition, previous studies have demonstrated that nAChRs including $\alpha 4 \beta 2$ and $\alpha 7$ are expressed in progenitor cells in embryonic mouse brain (Dwyer et al, 2008). These studies support our present findings that $\alpha 7 \mathrm{nAChRs}$ mediate the decreased proliferation of neuronal progenitors by $\mathrm{PNE}$ in the $\mathrm{VZ}$ and SVZ layers on E14 (Figure 2 and Supplementary Figure S1). Since this is a single and early time-point of $\mathrm{PNE}$, further studies are required to extrapolate the nAChR mechanism to either proliferation on E15 onwards or survival of these cells.

Nicotine can act as either a pro-apoptotic or anti-apoptotic agent, depending on the target cells investigated, the concentration used and the period of time it is applied (Dwyer et al, 2008; Zeidler et al, 2007). For example, the apoptotic effects of nicotine have been observed both in vivo and in vitro in the developing brain (Abreu-Villaca et al, 2004; Qiao et al, 2003). Continuous exposure to nicotine has been reported to have little effect on cell survival in neural progenitors in vitro (Takarada et al, 2012). Recent studies using DNA microarrays have shown that gestational nicotine exposure affects gene expression associated with cell adhesion and cell death/survival in the brains of adolescent rats (Cao et al, 2011, 2013; Wei et al, 2011). Although the effect of nicotine on neuronal migration has not yet been studied in detail, it has been reported that exposure to nicotine with intermittent hypoxia during gestation inhibited neuronal migration while nicotine alone (without intermittent hypoxia) had no effect (Zechel et al, 2005). These previous results are consistent with our present findings (Figure 2 and Supplementary Figure S1). In this study of BrdU labeling on E13, cell mitosis may be not affected but cell survival and migration could be affected by PNE from E14 to P0 since the cell counting was conducted on P7 or in adulthood. As a result shown in Figure $2 c$, there was no difference in the number of $\mathrm{BrdU}^{+}$cells labeled on E13 between control and PNE groups on P7, suggesting that PNE has little effects on neither cell survival or migration, but more detailed experiments, especially to test the effect on apoptosis, are needed in the future study.

During the development of the cerebral cortex, neuronal progenitor cells generate neurons by asymmetric and symmetric division (Tabata et al, 2012). Radial glial cells expressing Pax6 undergo symmetric proliferative division to amplify the progenitor pool, but also undergo asymmetric division to generate neurons, or a distinct class of progenitors, the short neural progenitors and intermediate progenitors that express Pax6 and Tbr2, respectively (Marin and Muller, 2014). Short neural progenitors and intermediate progenitors undergo symmetric division to produce pairs of neurons. These neurons migrate radially to the proper site, resulting in the formation of a layered structure with an inside-out pattern (Gupta et al, 2002). It has been established that changes in the number of neurons in the individual layers correlates with changes in the rate of neuron production (Dehay and Kennedy, 2007). In the present study, we found that PNE reduced the density of $\mathrm{BrdU}^{+}$cells (Figure 2d), in which mainly symmetric, proliferative division of neuronal progenitors were underway. In fact, we confirmed the enhanced downregulation due to PNE of both types of neural progenitors in the $\mathrm{VZ}$ and $\mathrm{SVZ}$ depending on the gestation period (Figure 3).

In the cortical progenitors, proliferation and growth arrest are regulated by a balance of extrinsic and intrinsic signals that direct the entry, progression into, and exit from the cell cycle. Specifically, it has been found that the number of neurons derived from the progenitor cells is determined by two cell cycle parameters: the rate of cell cycle progression and the balance between cell cycle re-entry and exit (Dehay and Kennedy, 2007). Many studies have demonstrated that dysregulation of the cell cycle in proliferating cells impacts not only the number of neurons, cytoarchitecture and brain development, but also adult behavior (Lee et al, 2008; Mitsuhashi et al, 2010; Wu et al, 2014). There are contradictory reports regarding the effect of nicotine on the cell cycle. Although some groups have reported that nicotine stimulates the cell cycle progression of vascular smooth muscle cells, lung epithelial cells, pre-osteoblastic cells (Chu et al, 2005; Sato et al, 2008), others have demonstrated that nicotine has an inhibitory effect in lymphocytes and neurospheres (Takarada et al, 2012). It is plausible that nicotine may impinge on cell cycle progression in distinct cell types through different mechanisms. In our present study, cumulative BrdU labeling demonstrated that both the S-phase and entire cell cycle were longer in PNE mice than in the control group (Supplementary Figure S2 and Table 1). Our findings suggest that PNE in mice inhibits cell cycle progression of neuronal progenitor cells in vivo.

Lastly, we conducted pharmacological experiments with DCS, an NMDA receptor partial agonist, to see if the cognitive and emotional impairments in PNE mice were due to hypofunction of glutamatergic neurons in the PFC. We showed that PNE impaired attentional function and behavioral flexibility in adulthood, as evident by enhanced LI and deficient extinction recall (Figure $4 \mathrm{a}$ and b). Several mental disorders including $\mathrm{AD} / \mathrm{HD}$ and schizophrenia exhibit impairment of attentional function and behavioral flexibility, which is associated with malfunction of the PFC (Leech and Sharp, 2014). In particular, neuronal dysfunction in the medial PFC is linked to cognitive function (Maren et al, 2013), social activity (Wall et al, 2012), and anxiety-like behavior (Adhikari et al, 2011).

DCS is reported to have some positive effects in treating patients with neuropsychiatric disorders such as posttraumatic stress disorder, social anxiety, as well as schizophrenia (Chue and Lalonde, 2014; Riaza Bermudo-Soriano et al, 2012). Furthermore, DCS facilitates fear extinction and modulates extracellular signal-regulated kinase signaling and ionotropic glutamate receptor protein expression in the medial PFC and amygdala in rats (Gupta et al, 2013). Consistent with these previous findings, we found in the present study that DCS microinjections into the PFC 
restored deficient extinction recall in the fear conditioning test (Figure 4f), but had no effect on the anxiety-like behavior in the elevated plus-maze test (Figure $4 \mathrm{~g}$ ), while systemic administration of DCS ameliorated both attentional deficits and anxiety-like behavior (Figure $4 \mathrm{c}-\mathrm{e}$ ). In addition to these behavioral data, we found that the glutamate content, basal level of extracellular glutamate, and the density of glutamatergic neurons were decreased in the PFC of PNE mice in adulthood (Figure 1). Thus, we assume that glutamatergic neurotransmission via NMDA receptors is impaired in PNE mice. Although we focused on glutamatergic neurodevelopment and function in the PFC in this study, we should explore the roles of GABAergic interneurons and investigate the potential contribution of brain regions other than the PFC. It would be also important to determine whether treatment with $\alpha 7 \mathrm{nAChR}$ antagonist for pregnant dams that received nicotine exposure during pregnancy could have some protective effects on the development of behavioral deficits in the offspring since the $\alpha 7 \mathrm{nAChR}$ antagonist MLA attenuated the PNE-induced decrease in $\mathrm{BrdU}^{+}$cells in the brains of offspring.

Taken together, our present findings suggest that PNE inhibits the cell cycle progression of neuronal progenitor cells, which could be associated with the reduction of glutamatergic neurons in the PFC in adulthood. The reduced glutamatergic function in the PFC may contribute to the development of aberrant behaviors such as deficient extinction recall in PNE mice, because microinjections of DCS into the PFC improved this behavioral deficit. Anxiety-related behavior in PNE mice was ameliorated by systemic treatment with DCS, but not by microinjections into the PFC. Accordingly, hypofunction of glutamatergic neurons in brain regions other than the PFC may be involved in the emotional deficits induced by PNE (Riaza Bermudo-Soriano et al, 2012). For example, some studies reported that PNE altered glutamatergic neurotransmission in the hippocampus and amygdala, contributing to the abnormal neurobehavioral outcomes (Jiang and Role, 2008; Parameshwaran et al, 2012).

One of the issues regarding PNE model used in the present study is that pregnant mice drinking nicotine solution ingest approximately half of the liquids of those drinking vehicle ( $2 \%$ sucrose), the result being consistent with previous studies (Alkam et al, 2013b; Pauly et al, 2004). Accordingly, one might concern that PNE mice are malnourished (too little water during development), which could contribute to the observed effects in the offspring. We believe, however, this is less likely because food was freely available during PNE from E14 to P0, and food intake and body weight of dam were not different between control and PNE groups. Further, there was no difference in the number and body weight of pups between control and PNE groups (Alkam et al, 2013b; Pauly et al, 2004). Nevertheless, to exclude the possible contribution of malnutrition in PNE-induced brain dysfunction in the offspring, further studies to analyze nutritional status of PNE mice would be required.

Our behavioral findings have two implications. First, our working hypothesis for the mechanism of brain dysfunction induced by PNE is supported by the behavioral and pharmacological experiments with DCS as discussed above. Second, and most importantly, our findings also suggest that NMDA receptor partial agonists may be a novel and effective treatment for impaired attentional function, behavioral flexibility, and anxiety in patients with $\mathrm{AD} / \mathrm{HD}$ or schizophrenia (Chue and Lalonde, 2014; Rapp et al, 2013). Accordingly, further studies using the PNE mouse model are warranted to clarify the pathophysiology and to provide the conceptual framework for drug discovery in neuropsychiatric disorders such as $\mathrm{AD} / \mathrm{HD}$ and schizophrenia.

\section{FUNDING AND DISCLOSURE}

This study was supported by Grants-in-Aids for Scientific Research (22248033, 22659213, 24590304, 25116515, 26293053, 26460240, and 26670121) from the Japan Society for the Promotion of Science (JSPS); by the 'Academic Frontier' Project for Private Universities (2007-2011) from the Ministry of Education, Culture, Sports, Science and Technology of Japan (MEXT); by the "Integrated Research on Neuropsychiatric Disorders' and 'Bioinformatics for Brain Sciences' carried out under the SRPBS from MEXT, by the Research on Regulatory Science of Pharmaceuticals and Medical Devices from the Ministry of Health and Labour Sciences from the Ministry of Health, Labour and Welfare, Japan (MHLW); by a grant from the joint research project under the Japan-Korea basic scientific cooperation program (JSPS); by a Research Grant from the SRF. The authors declare no conflict of interest.

\section{REFERENCES}

Abreu-Villaca Y, Seidler FJ, Slotkin TA (2004). Does prenatal nicotine exposure sensitize the brain to nicotine-induced neurotoxicity in adolescence? Neuropsychopharmacology 29: 1440-1450.

Adhikari A, Topiwala MA, Gordon JA (2011). Single units in the medial prefrontal cortex with anxiety-related firing patterns are preferentially influenced by ventral hippocampal activity. Neuron 71: 898-910.

Alkam T, Hiramatsu M, Mamiya T, Aoyama Y, Nitta A, Yamada K et al (2011). Evaluation of object-based attention in mice. Behav Brain Res 220: 185-193.

Alkam T, Kim HC, Hiramatsu M, Mamiya T, Aoyama Y, Nitta A et al (2013a). Evaluation of emotional behaviors in young offspring of C57BL/6J mice after gestational and/or perinatal exposure to nicotine in six different time-windows. Behav Brain Res 239: 80-89.

Alkam T, Kim HC, Mamiya T, Yamada K, Hiramatsu M, Nabeshima T (2013b). Evaluation of cognitive behaviors in young offspring of C57BL/6J mice after gestational nicotine exposure during different time-windows. Psychopharmacology (Berl) 230: 451-463.

Aoyama Y, Mouri A, Toriumi K, Koseki T, Narusawa S, Ikawa N et al (2014). Clozapine ameliorates epigenetic and behavioral abnormalities induced by phencyclidine through activation of dopamine D1 receptor. Int J Neuropsychopharmacol 17: 723-737.

Arnsten AF, Paspalas CD, Gamo NJ, Yang Y, Wang M (2010). Dynamic network connectivity: a new form of neuroplasticity. Trends Cogn Sci 14: 365-375.

Burgos-Robles A, Vidal-Gonzalez I, Santini E, Quirk GJ (2007). Consolidation of fear extinction requires NMDA receptordependent bursting in the ventromedial prefrontal cortex. Neuron 53: $871-880$

Cao J, Dwyer JB, Mangold JE, Wang J, Wei J, Leslie FM et al (2011). Modulation of cell adhesion systems by prenatal nicotine exposure in limbic brain regions of adolescent female rats. Int $J$ Neuropsychopharmacol 14: 157-174. 
Cao J, Wang J, Dwyer JB, Gautier NM, Wang S, Leslie FM et al (2013). Gestational nicotine exposure modifies myelin gene expression in the brains of adolescent rats with sex differences. Transl Psychiatry 3: e247.

Chu M, Guo J, Chen CY (2005). Long-term exposure to nicotine, via ras pathway, induces cyclin D1 to stimulate G1 cell cycle transition. J Bio Chem 280: 6369-6379.

Chue P, Lalonde JK (2014). Addressing the unmet needs of patients with persistent negative symptoms of schizophrenia: emerging pharmacological treatment options. Neuropsychiatr Dis Treat 10: 777-789.

Dehay C, Kennedy H (2007). Cell-cycle control and cortical development. Nat Rev Neurosci 8: 438-450.

Dwyer JB, Broide RS, Leslie FM (2008). Nicotine and brain development. Birth Defects Res C Embryo Today 84: 30-44.

Dwyer JB, McQuown SC, Leslie FM (2009). The dynamic effects of nicotine on the developing brain. Pharmacol Ther 122: 125-139.

Englund C, Fink A, Lau C, Pham D, Daza RA, Bulfone A et al (2005). Pax6, Tbr2, and Tbr1 are expressed sequentially by radial glia, intermediate progenitor cells, and postmitotic neurons in developing neocortex. J Neurosci 25: 247-251.

Franklin KBJ, Paxinos G (2008). The Mouse Brain in Stereotaxiccoordinates, Compact, 3rd edn. Academic Press: San Diego.

Fukumitsu H, Ohtsuka M, Murai R, Nakamura H, Itoh K, Furukawa S (2006). Brain-derived neurotrophic factor participates in determination of neuronal laminar fate in the developing mouse cerebral cortex. J Neurosci 26: 13218-13230.

Gupta A, Tsai LH, Wynshaw-Boris A (2002). Life is a journey: a genetic look at neocortical development. Nat Rev Genet 3: 342-355.

Gupta SC, Hillman BG, Prakash A, Ugale RR, Stairs DJ, Dravid SM (2013). Effect of D-cycloserine in conjunction with fear extinction training on extracellular signal-regulated kinase activation in the medial prefrontal cortex and amygdala in rat. Eur J Neurosci 37: 1811-1822.

He N, Wang Z, Wang Y, Shen H, Yin M (2013). ZY-1, a novel nicotinic analog, promotes proliferation and migration of adult hippocampal neural stem/progenitor cells. Cell Mol Neurobiol 33: 1149-1157.

Herr KJ, Herr DR, Lee CW, Noguchi K, Chun J (2011). Stereotyped fetal brain disorganization is induced by hypoxia and requires lysophosphatidic acid receptor 1 (LPA1) signaling. Proc Natl Acad Sci USA 108: 15444-15449.

Jiang L, Role LW (2008). Facilitation of cortico-amygdala synapses by nicotine: activity-dependent modulation of glutamatergic transmission. J Neurophysiol 99: 1988-1999.

Kaczorowski CC, Davis SJ, Moyer JR Jr (2012). Aging redistributes medial prefrontal neuronal excitability and impedes extinction of trace fear conditioning. Neurobiol Aging 33: 1744-1757.

Kaneko T, Mizuno N (1994). Glutamate-synthesizing enzymes in GABAergic neurons of the neocortex: a double immunofluorescence study in the rat. Neuroscience 61: 839-849.

Labrie V, Wang W, Barger SW, Baker GB, Roder JC (2010). Genetic loss of D-amino acid oxidase activity reverses schizophrenia-like phenotypes in mice. Genes Brain Behav 9: 11-25.

Lee CT, Chen J, Hayashi T, Tsai SY, Sanchez JF, Errico SL et al (2008). A mechanism for the inhibition of neural progenitor cell proliferation by cocaine. PLoS Med 5: e117.

Leech R, Sharp DJ (2014). The role of the posterior cingulate cortex in cognition and disease. Brain 137: 12-32.

Makris N, Seidman LJ, Valera EM, Biederman J, Monuteaux MC, Kennedy DN et al (2010). Anterior cingulate volumetric alterations in treatment-naive adults with ADHD: a pilot study. J Atten Disord 13: 407-413.

Maren S, Phan KL, Liberzon I (2013). The contextual brain: implications for fear conditioning, extinction and psychopathology. Nat Rev Neurosci 14: 417-428.
Marin O, Muller U (2014). Lineage origins of GABAergic versus glutamatergic neurons in the neocortex. Curr Opin Neurobiol 26C: $132-141$.

Matta SG, Balfour DJ, Benowitz NL, Boyd RT, Buccafusco JJ, Caggiula AR et al (2007). Guidelines on nicotine dose selection for in vivo research. Psychopharmacology 190: 269-319.

Mitsuhashi T, Yonemoto J, Sone H, Kosuge Y, Kosaki K, Takahashi $\mathrm{T}$ (2010). In utero exposure to dioxin causes neocortical dysgenesis through the actions of p27Kip1. Proc Natl Acad Sci USA 107: 16331-16335.

Morgan MA, Romanski LM, LeDoux JE (1993). Extinction of emotional learning: contribution of medial prefrontal cortex. Neurosci Lett 163: 109-113.

Moser PC, Hitchcock JM, Lister S, Moran PM (2000). The pharmacology of latent inhibition as an animal model of schizophrenia. Brain Res Brain Res Rev 33: 275-307.

Murai R, Noda Y, Matsui K, Kamei H, Mouri A, Matsuba K et al (2007). Hypofunctional glutamatergic neurotransmission in the prefrontal cortex is involved in the emotional deficit induced by repeated treatment with phencyclidine in mice: implications for abnormalities of glutamate release and NMDA-CaMKII signaling. Behav Brain Res 180: 152-160.

Niwa M, Kamiya A, Murai R, Kubo K, Gruber AJ, Tomita K et al (2010). Knockdown of DISC1 by in utero gene transfer disturbs postnatal dopaminergic maturation in the frontal cortex and leads to adult behavioral deficits. Neuron 65: 480-489.

Njung'e K, Handley SL (1991). Evaluation of marble-burying behavior as a model of anxiety. Pharmacol Biochem Behav 38: 63-67.

Pagani LS (2014). Environmental tobacco smoke exposure and brain development: the case of attention deficit/hyperactivity disorder. Neurosci Biobehav Rev 44: 195-205.

Parameshwaran K, Buabeid MA, Karuppagounder SS, Uthayathas S, Thiruchelvam K, Shonesy B et al (2012). Developmental nicotine exposure induced alterations in behavior and glutamate receptor function in hippocampus. Cell Mol Life Sci 69: 829-841.

Pauly JR, Slotkin TA (2008). Maternal tobacco smoking, nicotine replacement and neurobehavioural development. Acta Paediatr 97: 1331-1337.

Pauly JR, Sparks JA, Hauser KF, Pauly TH (2004). In utero nicotine exposure causes persistent, gender-dependant changes in locomotor activity and sensitivity to nicotine in $\mathrm{C} 57 \mathrm{Bl} / 6$ mice. Int $J$ Dev Neurosci 22: 329-337.

Pellow S, Chopin P, File SE, Briley M (1985). Validation of open: closed arm entries in an elevated plus-maze as a measure of anxiety in the rat. $J$ Neurosci Methods 14: 149-167.

Penagarikano O, Abrahams BS, Herman EI, Winden KD, Gdalyahu A, Dong $\mathrm{H}$ et al (2011). Absence of CNTNAP2 leads to epilepsy, neuronal migration abnormalities, and core autism-related deficits. Cell 147: 235-246.

Qiao D, Seidler FJ, Violin JD, Slotkin TA (2003). Nicotine is a developmental neurotoxicant and neuroprotectant: stage-selective inhibition of DNA synthesis coincident with shielding from effects of chlorpyrifos. Brain Res Dev Brain Res 147: 183-190.

Rapp A, Dodds A, Walkup JT, Rynn M (2013). Treatment of pediatric anxiety disorders. Ann N Y Acad Sci 1304: 52-61.

Riaza Bermudo-Soriano C, Perez-Rodriguez MM, Vaquero-Lorenzo C, Baca-Garcia E (2012). New perspectives in glutamate and anxiety. Pharmacol Biochem Behav 100: 752-774.

Sato T, Abe T, Nakamoto N, Tomaru Y, Koshikiya N, Nojima J et al (2008). Nicotine induces cell proliferation in association with cyclin D1 up-regulation and inhibits cell differentiation in association with p53 regulation in a murine pre-osteoblastic cell line. Biochem Biophys Res Commun 377: 126-130.

Schneider T, Ilott N, Brolese G, Bizarro L, Asherson PJ, Stolerman IP (2011). Prenatal exposure to nicotine impairs performance of the 5-choice serial reaction time task in adult rats. Neuropsychopharmacology 36: 1114-1125. 
Shen X, Liu Y, Xu S, Zhao Q, Wu H, Guo X et al (2014). Menin regulates spinal glutamate-GABA balance through GAD65 contributing to neuropathic pain. Pharmacol Rep 66: 49-55.

Shingo AS, Kito S (2005). Effects of nicotine on neurogenesis and plasticity of hippocampal neurons. J Neural Transm 112: 1475-1478.

Tabata H, Yoshinaga S, Nakajima K (2012). Cytoarchitecture of mouse and human subventricular zone in developing cerebral neocortex. Exp Brain Res 216: 161-168.

Takarada T, Nakamichi N, Kitajima S, Fukumori R, Nakazato R, Le NQ et al (2012). Promoted neuronal differentiation after activation of alpha4/beta2 nicotinic acetylcholine receptors in undifferentiated neural progenitors. PloS One 7: e46177.

Toriumi K, Mouri A, Narusawa S, Aoyama Y, Ikawa N, Lu L et al (2012). Prenatal NMDA receptor antagonism impaired proliferation of neuronal progenitor, leading to fewer glutamatergic neurons in the prefrontal cortex. Neuropsychopharmacology 37: 1387-1396.

Vuillermot S, Joodmardi E, Perlmann T, Ogren SO, Feldon J, Meyer U (2012). Prenatal immune activation interacts with genetic Nurr1 deficiency in the development of attentional impairments. J Neurosci 32: 436-451.

Wall VL, Fischer EK, Bland ST (2012). Isolation rearing attenuates social interaction-induced expression of immediate early gene protein products in the medial prefrontal cortex of male and female rats. Physiol Behav 107: 440-450.

Wei J, Wang J, Dwyer JB, Mangold J, Cao J, Leslie FM et al (2011). Gestational nicotine treatment modulates cell death/survivalrelated pathways in the brains of adolescent female rats. Int $J$ Neuropsychopharmacol 14: 91-106.

Wu X, Gu X, Han X, Du A, Jiang Y, Zhang X et al (2014). A novel function for Foxm1 in interkinetic nuclear migration in the developing telencephalon and anxiety-related behavior. J Neurosci 34: 1510-1522.

Yamada D, Zushida K, Wada K, Sekiguchi M (2009). Pharmacological discrimination of extinction and reconsolidation of contextual fear memory by a potentiator of AMPA receptors. Neuropsychopharmacology 34: 2574-2584.

Zechel JL, Gamboa JL, Peterson AG, Puchowicz MA, Selman WR, Lust WD (2005). Neuronal migration is transiently delayed by prenatal exposure to intermittent hypoxia. Birth Defects Res B Dev Reprod Toxicol 74: 287-299.

Zeidler R, Albermann K, Lang S (2007). Nicotine and apoptosis. Apoptosis 12: 1927-1943.

Zhu J, Zhang X, Xu Y, Spencer TJ, Biederman J, Bhide PG (2012). Prenatal nicotine exposure mouse model showing hyperactivity, reduced cingulate cortex volume, reduced dopamine turnover, and responsiveness to oral methylphenidate treatment. J Neurosci 32: $9410-9418$. 